\title{
Value of bronchoalveolar lavage in the diagnosis of pulmonary infection in acquired immune deficiency syndrome
}

\author{
MARILYN ORENSTEIN, CAROLYN A WEBBER, MARY CASH, \\ ALBERT E HEURICH \\ From the Departments of Medicine and Pathology, Downstate Medical Center, State University Hospital, and \\ King's County Hospital Center, Brooklyn, New York, USA
}

\begin{abstract}
Seventy five patients with pulmonary disease and suspected acquired immune deficiency syndrome (AIDS) underwent fibreoptic bronchoscopy with bronchoalveolar lavage. Of 54 cases of Pneumocystis carinii pneumonia, 53 (98\%) were diagnosed by bronchoalveolar lavage. Complications were recorded in 12 instances and included pneumothorax in two and transient increase in fever and hypoxaemia in the remainder. Bronchoalveolar lavage is a safe, easy, and effective procedure for diagnosing pneumocystis pneumonia in patients at high risk of AIDS and should be done routinely when fibreoptic bronchoscopy is performed in such patients.
\end{abstract}

The problem of opportunistic infections in acquired immune deficiency syndrome (AIDS) has resulted in the application of several techniques using fibreoptic bronchoscopy to identify the offending agents. One of these techniques, bronchoalveolar lavage, has emerged as an important method in evaluating both inflammatory and immune processes in lung disease. ${ }^{1-4}$ Earlier papers on the diagnosis of Pneumocystis carinii pneumonia using bronchoalveolar lavage in immunosuppressed patients have reported results from relatively small numbers of patients. ${ }^{56}$ Reports from other groups have shown high yields for a positive diagnosis of pneumocystis pneumonia on the basis of transbronchial biopsy. ${ }^{2} 7$ In preliminary work we found a high rate of positive identification of Pneumocystis carinii from bronchoalveolar lavage and proceeded to apply the technique to a larger group of patients with AIDS or a high suspicion of AIDS.

\section{Methods}

From July 1983 to September 198491 patients were investigated by the pulmonary medicine division at

\footnotetext{
Address for reprint requests: Dr Marilyn Orenstein, Department of Medicine, Morristown Memorial Hospital, 151 Madison Avenue, Morristown, New Jersey 07960, USA.
}

Accepted 25 November 1985
Downstate Medical Center-Kings County Hospital, New York City, because of an abnormal chest radiograph and known or suspected AIDS. ${ }^{8}$ Seventy five patients, the subjects of this report, underwent fibreoptic bronchoscopy. Repeat bronchoscopies in three of the 75 patients resulted in 78 procedures over 14 months. Eight patients had documented AIDS at the time of bronchoscopy on the basis of the criteria of the US Center for Disease Control (CDC). The 62 patients with CDC risk factors for AIDS among the remaining 67 patients included 32 intravenous drug users, two female consorts of patients with AIDS, homosexual males, and 20 immigrants from Haiti (at the time of the study Haitians were classified as being at risk of acquiring AIDS; they are no longer so classified). Five patients had no known risk factors for AIDS. There were 14 women and 61 men ranging in age from 19 to 60 years. Sixty nine of 75 patients had fever and 73 of 75 had an abnormal chest radiograph. Other frequent symptoms included weight loss, dyspnoea, and cough. Three patients were receiving treatment for documented tuberculosis, 49 patients had oral candidiasis, 30 had diffuse lymphadenopathy, six had orogenital herpes simplex and two had oral herpes simplex (table 1).

Diffuse abnormalities on the chest radiograph, cough, and dyspnoea were found with greater frequency among patients shown later to have pneumocystis pneumonia, whereas diffuse lymphadenopathy was found to be more important in the 
Table 1 Clinical and laboratory findings in patients with and without Pneumocystis carinii pneumonia (PCP).

\begin{tabular}{|c|c|c|}
\hline & $\begin{array}{l}\text { With } \\
P C P\end{array}$ & $\begin{array}{l}\text { Without } \\
\text { PCP }\end{array}$ \\
\hline Age (mean) & 34 & 31 \\
\hline \multicolumn{3}{|l|}{ Sex } \\
\hline $\begin{array}{l}\% \text { male } \\
\% \text { female }\end{array}$ & $\begin{array}{l}85.2 \\
14.8\end{array}$ & $\begin{array}{l}71.4 \\
28.5\end{array}$ \\
\hline \multicolumn{3}{|l|}{$\%$ with risk factors } \\
\hline Drug addiction & 57.4 & 42.9 \\
\hline Female consorts & 3.7 & 4.8 \\
\hline Haitian & 22.2 & 38.1 \\
\hline Homosexual & 9.3 & 23.8 \\
\hline No risk factor & 11.1 & 0.0 \\
\hline \multicolumn{3}{|c|}{$\%$ with symptoms and signs } \\
\hline Fever & 96.3 & 89.5 \\
\hline Weight loss & 79.2 & 89.5 \\
\hline Cough & 81.1 & 63.2 \\
\hline Dyspnoea & 83.0 & 63.2 \\
\hline Lymphadenopathy & 31.5 & 65.0 \\
\hline Oral thrush & 63.0 & 78.9 \\
\hline Oral herpes & 2.0 & 5.3 \\
\hline Orogenital herpes & 7.7 & 10.5 \\
\hline \multicolumn{3}{|c|}{$\%$ with radiographic features } \\
\hline Diffuse & 94.4 & 85.7 \\
\hline Focal & 1.9 & 14.3 \\
\hline Normal & 3.7 & 0.0 \\
\hline Adenopathy & 1.9 & 28.6 \\
\hline Effusion & 0.0 & 9.5 \\
\hline Cavity & 0.0 & 4.8 \\
\hline \multirow{2}{*}{\multicolumn{3}{|c|}{$\begin{array}{l}\text { Leucocyte count } \\
\quad\left(\text { mean (SD), } \times 10^{9} / 1\right) \\
\text { Arterial blood gases (mean (SD)) }\end{array}$}} \\
\hline & & \\
\hline $\begin{array}{l}\mathrm{PaO}_{2} \mathrm{~mm} \mathrm{Hg} \\
\mathrm{PaCO}_{2} \\
\mathrm{pH}\end{array}$ & $\begin{array}{l}67.0(13.0) \\
33.6(5.4) \\
7.45(0.04)\end{array}$ & $\begin{array}{l}73.3(17.5) \\
29.8(7.3)^{* * *} \\
7.45(0.11)\end{array}$ \\
\hline
\end{tabular}

${ }^{*} \mathrm{p}<0.02\left(\chi^{2}\right.$ test $) ;{ }^{* *} \mathrm{p}<0.01$ ( $\chi^{2}$ test $) ;{ }^{* *} \mathrm{p}<0.05$ ( $t$ test $)$.

$\mathrm{PaO}_{2}, \mathrm{PaCO}_{2}$-arterial oxygen and carbon dioxide tensions.

Conversion: Tradition to SI units-Blood gases: $1 \mathrm{~mm} \mathrm{Hg}=7.5 \mathrm{kPa}$

group without pneumocystis pneumonia. Leucocyte count, arterial $\mathrm{pH}$, and arterial oxygen tension did not significantly differ between patients with proved pneumocystis and those with other opportunistic infections (table 1). Arterial carbon dioxide tension in the group without pneumocystis pneumonia was significantly lower $(p<0.05)$ than in the group with pneumocystis pneumonia (Table 1). Three patients required ventilatory support and one patient had severe uncorrectable thrombocytopenia.

Statistical evaluation was performed with Student's $t$ test and $\chi^{2}$ analysis. A p value of less than 0.05 was accepted as significant.

\section{PULMONARYLAVAGE}

Patients had premedication with parenteral atropine and pentobarbitone sodium. Topical $2 \%$ lignocaine was applied to the airways and oxygen was administered. Patients on respirators had an endotracheal tube adaptor for bronchoscopy. Bronchoalveolar lavage was performed by the method of Kelley et al. ${ }^{6}$ Subsegmental lung lavage of right middle lobe or lingula was performed with three to six $30 \mathrm{ml}$ aliquots of normal saline (total $100-180 \mathrm{ml}$ ) with immediate syringe aspiration. Lavage was discontinued if the ${ }^{ \pm}$. return fluid aspirate lagged behind instilled volume by $\overrightarrow{\vec{F}}$ more than $50 \mathrm{ml}$. Transbronchial brushings, biopsy? specimens, and washings were obtained.

\section{LAVAGE FLUID SPECIMENS}

One aliquot of lavage fluid was treated for Papa- $\cong$ nicolaou, Gram-Weigert and Gomori-methenaminew silver staining. Specimens of lavage fluid for cyto- $\vec{\circ}$ logical examination were mixed with an equal volumeof $70 \%$ ethanol and centrifuged for 10 minutes at $\vec{\omega}$ $3000 \mathrm{rev} / \mathrm{min}$. The sediment was smeared on four to seven albuminised slides that were wet fixed in $95 \% \times$ ethanol. The smeared slides were then stained with $\Rightarrow$ the Papanicolaou, Gram-Weigert, and Gom-ir orimethenamine silver stains. Smears were screened ${ }_{A}^{\omega}$ by cytological technicians and reviewed by a cyto- $O$ pathologist (CAW) for the presence of fungi, Pneu- mocystis carinii, viral inclusions, and malignant or $\overrightarrow{-}$ atypical cells. Another aliquot was stained and cultured for mycobacteria, fungi, bacteria, and viruses and stained for Legionella pneumophila antigen.

\section{OTHER BRONCHOSCOPY SPECIMENS}

Bronchial washings and transbronchial brushings were studied in the same manner as the lavage fluid. In addition, the bronchial washings were sent for fun-0 gal, bacterial, mycobacterial, and viral cultures. $\stackrel{\otimes}{\odot}$ Histological sections of material obtained by trans $-\vec{A}$ bronchial biopsy were examined after staining with hematoxylin-eosin, Gram-Weigert, Ziehl-Neelsen, and Gomorimethenamine silver.

\section{PROCEDURE FOR STERILISATION OF THE BRONCHOSCOPE}

During bronchoscopy staff routinely wore gloves, $\stackrel{\times}{\circ}$ gowns, hats, masks, and goggles and followed the 3 . precautions for clinical and laboratory staffs outlined

Table 2 Bronchoalveolar lavage results

\begin{tabular}{|c|c|c|}
\hline Pneumocystis carinii & 53 & $\begin{array}{l}\text { Coexistent infections } \\
5 \text { cytomegalovirus } \\
2 \text { herpes simplex } \\
2 M \text { avium intracellulare }\end{array}$ \\
\hline Viruses & \multirow{3}{*}{\multicolumn{2}{|c|}{$\begin{array}{l}1 \\
1\end{array}$}} \\
\hline Herpes simplex injection & & \\
\hline $\begin{array}{l}\text { Adenovirus } \\
\text { Mycobacteria }\end{array}$ & & \\
\hline$M$ tuberculosis & \multicolumn{2}{|l|}{8} \\
\hline Fungi & \multirow{2}{*}{\multicolumn{2}{|c|}{2}} \\
\hline $\begin{array}{l}\text { Cryptococcus neoformans } \\
\text { Bacteria }\end{array}$ & & \\
\hline Haemophilus influenzae & \multicolumn{2}{|l|}{1} \\
\hline $\begin{array}{l}\text { Lavage results } \\
\text { Positive } \\
\text { Negative }\end{array}$ & \multicolumn{2}{|c|}{$\begin{array}{l}66 \\
12 \text { (see text) }\end{array}$} \\
\hline Total lavage procedures & \multicolumn{2}{|l|}{78} \\
\hline
\end{tabular}


by the CDC. ${ }^{9}$ A separate bronchoscope has been used for patients with AIDS or suspected AIDS since July 1983, when this study began. The bronchoscope was washed with soap and water and the inside lumen was brushed. It was then rinsed with water and $30 \%$ alcohol for drying. The bronchoscope was then subjected to ethylene oxide sterilisation.

\section{Results}

Bronchoalveolar lavage gave diagnostic information in 66 of 78 instances (85\%) (Table 2). $P$ carinii was found in 53 patients and was well demonstrated on both Papanicolaou and Gram-Weigert smears. Nine of the 53 patients with $P$ carinii had more than one pathogen obtained by bronchoalveolar lavage. These included five with cytomegalovirus infection, two with herpes simplex, and two with Mycobacterium avium intracellulare infection. In 13 additional patients other organisms were obtained on BAL. They included eight patients with mycobacterial infection ( $M$ tuberculosis cultured from lavage fluid); two with fungal infection (Cryptococcus neoformans demonstrated on a smear and cultured from the lavage fluid); two with viral pathogens (one herpesvirus from a patient with herpes simplex who had viral inclusion bodies in the lavage fluid and a positive viral culture and one adenovirus); one with $H$ influenzae. Confirmation that a correct diagnosis had been made from the lavage fluid was obtained by transbronchial biopsy, lung biopsy, necrospy or observation of the response to specific treatment of the pathogen obtained. Lung biopsy tissue confirmation of the positive lavage results for $P$ carinii was available in 34 of 53 cases (29 transbronchial biopsies, one open lung biopsy, four necropsies). The eight patients with $M$ tuberculosis demonstrated in the lavage fluid had cultures of material from other sites that were positive for $M$ tuberculosis or had granulomas on histological examination of the lung. The two patients in whom cryptococcus was found in the lavage fluid yield positive cultures from the central nervous system and one had postmortem confirmation of the lavage diagnosis.

The one patient with $H$ influenzae infection responded initially to specific treatment for $H$ influenzae but about six weeks later returned to the hospital with evidence of disseminated cryptococcal infection (confirmed by examination of spinal fluid and lung biopsy specimen).

The two patients with viral infection (one adenovirus, one herpesvirus) were patients with previously documented AIDS and both died without postmortem examination.

In the 12 patients in whom no pathogen was obtained from the lavage fluid pathogens were obtained from other sites. Seven patients with mycobacterial infection (four $M$ tuberculosis, two $M$ avium intracellulare, one unidentified mycobacterium (cultures lost)) had organisms identified from transbronchial biopsy, or open lung biopsy cultures (sometimes from more than one of these). $P$ carinii was found in open lung biopsy specimens from one patient. In the remaining four patients no pulmonary pathogen was found; disseminated cryptococcal infection was, however, demonstrated in one case by cerebrospinal fluid and bone marrow culture, gastrointestinal Kaposi sarcoma in one case, and Staphylococcus aureus endocarditis (positive blood cultures) in one case. The last patient (previously documented as having AIDS) refused all further diagnostic procedures.

Fifty three of the 54 patients with $P$ carinii pneumonia were diagnosed by bronchoalveolar lavage, which thus had a diagnostic sensitivity of $98 \%$ (table 3 ). In the single patient with negative results from lavage open lung biopsy was diagnostic. In patients with $P$ carinii proved by bronchoalveolar lavage the organism was also found in 29 of 39 transbronchial biopsy specimens, 40 of 53 bronchial washings, and 20 of 48 brushings (table 3 ). Of the 10 negative transbronchial biopsy specimens, six were inadequate with no identifiable alveoli. Bronchoalveolar lavage was exclusively positive in seven of 53 patients $(13 \%)$ with $P$ carinii. Complications of bronchoalveolar lavage were minimal and consisted of transient increase in fever in five patients and hypoxaemia in five. Two pneumothoraces requiring chest tubes were observed but both patients had also had transbronchial biopsy performed.

\section{Discussion}

In view of a multitude of diagnostic techniques ${ }^{10-17}$ and of previous studies advocating the use of bronchoalveolar lavage in diagnosing $P$ carinii infection in

Table 3 Proportion of specimens positive for Pneumocystis carinii from fibreoptic bronchoscopic procedures

\begin{tabular}{llllll}
\hline Procedure & Lavage & Biopsy & Wash & Brush & Combined bronchoscopic procedures \\
\hline Diagnostic & $53 / 54(98 \%)$ & $29 / 39(74 \%)$ & $40 / 53(76 \%)$ & $20 / 48(42 \%)$ & $53 / 54(98 \%)$ \\
Non-diagnostic & $1 / 54(2 \%)$ & $10 / 39^{*}(26 \%)$ & $13 / 53(24 \%)$ & $28 / 48(58 \%)$ & $1 / 54(2 \%)$ \\
\hline
\end{tabular}

*No alveoli seen in six of 10 bronchoscopy samples. 
immunosuppressed individuals with AIDS 717 and with other conditions, ${ }^{56}$ we sought to assess our own experience in diagnosing $P$ carinii infection by bronchoalveolar lavage in individuals with documented or suspected AIDS. In this study bronchoalveolar lavage provided a sensitive and effective means of diagnosing pneumocystis pneumonia. Fifty three of the 54 patients with pneumocystis infection $(98 \%)$ were diagnosed by bronchoalveolar lavage. Our results with bronchial brushings $(\mathbf{4 2} \%)$, bronchial washings $(76 \%)$, and transbronchial biopsy (74\%) showed varying sensitivities, but are similar to those reported by others. ${ }^{23717}$ Others have reported a sensitivity as high as $95 \%$ with transbronchial biopsy. ${ }^{1}$ Part of this discrepancy may be due to technical factors and probably reflects limited access to fluoroscopy. Specimens in six of 10 transbronchial biopsy specimens falsely negative for $P$ carinii showed no alveoli. Because bronchoalveolar lavage samples material from many alveoli it is more likely to yield a positive result. The higher yield of bronchoalveolar lavage in diagnosing infection may reflect the larger size of the area sampled by lavage.

Lung biopsy tissue confirmed the positive lavage results in 34 of 53 cases of pneumocystis infection $(64 \%)$. In the remaining 19 patients with lavage fluid positive for $P$ carinii lung tissue not obtained or insufficient or was negative, but 14 also had bronchial washings or brushings (or both) positive for $\boldsymbol{P}$ carinii. Furthermore, all 54 patients had clinical criteria for pneumonia as evidenced by hypoxaemia, fever, and diffuse abnormalities on the chest radiograph. In nine of 54 patients with $P$ carinii additional pulmonary pathogens were obtained by bronchoalveolar lavage (five cytomegalovirus, two herpesvirus, two $M$ avium intracellulare).

In the 21 patients without documented $P$ carinii bronchoalveolar lavage yielded organisms in 13 instances $(62 \%)$. Possibly other potential pathogens were missed in the two cases of presumptive viral pneumonia, since both patients had previously documented AIDS and died in hospital and no lung tissue was obtained. If these two and the four patients in the non-diagnostic lavage group from whom no pulmonary pathogen was obtained are added together and considered as potential "false negatives" for $P$ carinii, our yield from bronchoalveolar lavage would fall from $53 / 54(98 \%)$ to $53 / 60(88 \%)$. The figure of $88 \%$ is still a high yield and similar to that of the best studies. ${ }^{2717}$

Recent studies of bronchoalveolar lavage in immunosuppressed patients have suggested that it is useful in the diagnosis of mycobacterial disease. ${ }^{216} \mathrm{Our}$ study confirms these results by the finding of 17 instances of mycobacterial disease with lavage with positive smears and cultures in 10 cases $(60 \%)$.
A recently published combined multicentre retro-: spective study on the pulmonary complications of AIDS from a National Heart and Lung Institute workshop in the United States found a 79\% yielof from lavage specimens from the 178 patients in whom it was done. ${ }^{17} \mathrm{~A}$ similar but very small prospective study of only 16 patients found a sensitivity of $89 \%$ for the diagnosis of pneumocystis pneumonia. ${ }^{7}$ Oures yield of $98 \%$ for the diagnosis of pneumocystis infec $\overrightarrow{0}$ tion by lavage represents the best results so far that we are aware of.

We believe that this high yield reflects a combina tion of factors: in the first place, most patients with $P^{x}$ carinii had diffuse disease evident on the radiograph perhaps representing a large burden or organisms, and, secondly, the close working relationship betweens the pulmonary and the cytopathology departments ensured meticulous processing of all specimens. We believe that an adequately trained cytopathology $\vec{z}$ department and close communication with them arew prerequisites for the successful application of this technique.

In conclusion, bronchoalveolar lavage is a simple and effective technique that can be performed readily during fibreoptic bronchoscopy as a means of diagnosing pneumocystis pneumonia as well as other opportunistic infections in patients with AIDS or suspectedै AIDS.

\section{References}

1 Schiep F, Garay SM, Aranda C, Green J. Pneumocystis carinii pneumonia in the acquired immune deficiency. syndrome: diagnostic yield utilizing fibreoptic bron choscopy [abstract]. Am Rev Respir Dis 1983;127 supp:189.

2 Stover DE, Gellene R, Romano P, White D. Diagnosis of pulmonary disease in acquired immune deficiency syn 0 drome. Am Rev Respir Dis 1984;130:659-62.

3 Coleman DL, Dodek PM, Golden JA, Gold WM Murray JF. Diagnostic utility of fiberoptic bron choscopy in patients with Pneumocystis carinii pneu monia and the acquired immune deficiency syndrome Am Rev Respir Dis 1983;128:795-9.

4 Hunninghake GW, Godek JE, Kawanami O, Ferrans VJ, Crystal RG. Inflammatory and immune processes in the human lung in health and disease: evaluation by bronchoalveolar lavage. Am J Pathol 1979;97:149-206. W

5 Drew WL, Finley JN, Mintz L, Klein HZ. Diagnosis of Pneumocystis carinii pneumonia by bronchopulmonaryo lavage. JAMA 1974;230:713-5.

6 Kelley J, Landis JN, Davis GS, Trainer TD, Jakab GJ心 Green GM. Diagnosis of pneumonia due to Pneu: mocystis by subsegmental pulmonary lavage via the fibreoptic bronchoscope. Chest 1978;74:24-8.

7 Ognibene FP, Shelhamer J, Gill V, et al. The diagnosis of Pneumocystis carinii pneumonia in patients with the acquired immunodeficiency syndrome using sub segmental bronchoalveolar lavage. Am Rev Respir Dis 
1984;129:929-32.

8 Center for Disease Control Update on acquired immune deficiency syndrome (AIDS)-United States. Morbidity and Mortality Weekly Report 1982;31:507-14.

9 Anonymous. AIDS: precautions for clinical and laboratory staffs. Morbidity and Mortality Weekly Report 1982;31:577-9.

10 Zavala DC, Bedeel GN. Percutaneous lung biopsy with a cutting needle: an analysis of $\mathbf{4 0}$ cases and comparison with other biopsy techniques. Am Rev Respir Dis 1972;106:186-93.

11 Chaudhary J, Hughes WT, Feldman S, et al. Percutaneous transthoracic needle aspiration of the lung: diagnosing Pneumocystis carinii pneumonitis. Am J Dis Child 1977;131:902-7.

12 Rosen PP, Martini N, Armstrong D. Pneumocystis carinii pneumonia: diagnosis by lung biopsy. Am J Med 1975;58:794-802.
13 Anderson HA, Fontana RS. Transbronchoscopic lung biopsy for diffuse pulmonary diseases: techniques and results in 450 cases. Chest 1972;62:125-8.

14 Finley R, Kieff E, Thomsen S, et al. Bronchial brushing in the diagnosis of pulmonary disease in patients at risk for opportunistic infection. Am Rev Respir Dis 1974;109:379-87.

15 Repsher LH, Schroter G, Hammond WS. Diagnosis of Pneumocystis carinii pneumonitis by means of endobronchial brush biopsy. N Engl J Med 1972;287:340.

16 Stover DE, Zaman MB, Hajdu SI, Lange M, Gold J, Armstrong D. Bronchoalveolar lavage in the diagnosis of diffuse pulmonary infiltrates in the immunosuppressed host. Ann Intern Med 1984;101:1-7.

17 Murray JF, Felton CP, Garay SM, et al. Pulmonary complications of the acquired immunodeficiency syndrome: report of a National Heart, Lung and Blood Institute workshop. $N$ Engl J Med 1984;310:1682-8. 